\title{
REVIEW
}

\section{The future is now: early life events preset adult behaviour*}

\author{
A. V. Patchev, ' A. J. Rodrigues, ${ }^{2,3}$ N. Sousa, ${ }^{2,3}$ D. Spengler' and O. F. X. Almeida' \\ I Max Planck Institute of Psychiatry, Munich, Germany \\ 2 Life and Health Sciences Research Institute, University of Minho, Braga, Portugal \\ 3 ICVS/3B's - PT Government Associate Laboratory, Braga/Guimarães, Portugal
}

Received 4 May 2013, revision requested 3 June 2013 , revision received 10 June 2013, accepted 13 June 2013 Correspondence: O. F. X. Almeida, Max Planck Institute of Psychiatry, Kraepelinstrasse 2-10, 80804 Munich, Germany.

E-mail: osa@mpipsykl.mpg.de

* Based on a lecture delivered at the Acta Physiologica

Sympsoium on Metabolic Programming, August 2012, Helsinki, Finland.

\begin{abstract}
To consider the evidence that human and animal behaviours are epigenetically programmed by lifetime experiences. Extensive PubMed searches were carried out to gain a broad view of the topic, in particular from the perspective of human psychopathologies such as mood and anxiety disorders. The selected literature cited is complemented by previously unpublished data from the authors' laboratories. Evidence that physiological and behavioural functions are particularly sensitive to the programming effects of environmental factors such as stress and nutrition during early life, and perhaps at later stages of life, is reviewed and extended. Definition of stimulus- and function-specific critical periods of programmability together with deeper understanding of the molecular basis of epigenetic regulation will deliver greater appreciation of the full potential of the brain's plasticity while providing evidence-based social, psychological and pharmacological interventions to promote lifetime well-being.

Keywords adolescent obesity, behaviour, early life stress, epigenetics, psychopathology.
\end{abstract}

The future is now. From conception onwards, our physical and social environments trigger a series of biochemical, morphological and physiological responses that act on the genetic blueprint to adjust development and lifelong programs of somatic and mental function. This continuous gene-environment dialogue can lead to persistent 'anticipatory' changes in the phenotype. This essential process is frequently referred to as 'programming' and allows the organism to make homoeostatic adaptations (including resetting of physiological sensors and thresholds) that ensure compatibility with changing environments and demands and therefore survival. In some cases, however, programming may result in maladaptation due to inherent (genetic) constraints, asynchronous or exaggerated adjustments in the chain of responses leading to elicitation of an overt physiological or behavioural output, or inflexibility induced by a preceding (programming) event. Epigenetic mechanisms involving methylation or hydroxymethylation of DNA [at cytosine-phosphate-guanine dinucleotide sites $(\mathrm{CpG})]$ or post-translational chromatin modification (histone acetylation, methylation, ubiquitination, phosphorylation, sumoylation) - are emerging as a powerful way to explain long-term (or even lifetime) programming and reprogramming of phenotype. Other authors have provided comprehensive reviews of the mechanisms underlying the genome-environment dialogue and determination of phenotype (Meaney 2010, Hoffmann \& Spengler 2012, Baker-Andresen et al. 2013, Hunter \& McEwen 2013).

The term 'epigenome' refers to the ensemble of coordinated epigenetic marks that govern accessibility of the machinery driving gene expression to DNA. Specific histone modifications and DNA methylation reciprocally control each other's deposition whereby inaccessible genes are silenced and accessible ones can be actively transcribed. Importantly, epigenetic modifications such as DNA methylation do not alter the genetic sequence itself but control the accessibility of 
regulatory factors to the control regions of genes. Chromatin remodelling by histone modifications is generally considered to be reversible, allowing transient adaptations in physiology and behaviour. On the other hand, DNA methylation results in more stable, if not irreversible, changes that manifest themselves in long-term altered patterns of gene expression, often interpreted as the encoding of 'memories' into genes. It is important to emphasize at the outset, however, that epigenetic alterations in gene activity occur in a dynamic (sometimes transient) fashion (see Ptashne 2013). Not every stimulus necessarily evokes an epigenetic adjustment, even though the overall response may be influenced by previous (epigenetic trace leaving) experience. Interestingly, DNA methylation does not occur in all organisms (e.g. flies, worms); yet, all organisms survive by making immediate (acute) biochemical and physiological responses to multitudinal challenges received on a time scale ranging from milliseconds to hours or days, by primarily exploiting their genetically determined cellular hardware.

\section{The epigenetic dimension of neuroplasticity}

Epigenetic programming plays an important role in cancer but also in the regulation of the physiology and pathology of other proliferating cells. Although the view that memory could be encoded in DNA more than 40 years ago (Griffith \& Mahler 1969), the idea that postmitotic neurones have the potential to be epigenetically programmed by experience (learning) gained broad currency only in the last few years.

The developing brain is highly plastic during gestation and early postnatal life (Toga et al. 2006). It is estimated that the embryonic human brain grows by some 250000 new cells per minute (Cowan 1979) that eventually organize themselves into functional units. During the last trimester of pregnancy, synapses are formed at the rate of $40000 \mathrm{~min}^{-1}$ (Bourgeois 1997), and efficient transmission is ensured through myelination of axons. However, suggestions that the existence of windows ('sensitive' or 'critical' periods), during puberty and perhaps even beyond, when the architecture of the brain is reorganized in response to changing environments, is supported by neuroimaging studies that have revealed the dynamic growth and functional connectivity (during the first 2 years); also to be noted is that neurons in the human brain undergo extensive pruning and reorganization from early postnatal life right through early adulthood, but especially during puberty (Huttenlocher \& Dabholkar 1997, Levitt 2003, Knickmeyer et al. 2008, Gao et al. 2011, Jernigan et al. 2011). Moreover, it is now known that certain brain regions can produce new neurones even in adulthood (Eriksson et al. 1998,
Kempermann 2012), expanding the plastic potential of the brain in terms of connections and incorporation of new epigenetic information ( $\mathrm{Ma}$ et al. 2010, Castrén \& Hen 2013, Mateus-Pinheiro et al. 2013). Thus, experiential memories can be laid down through epigenetic marking (DNA and histone memories) and/ or histomorphological adaptations (structural memories).

There is accumulating evidence that programming of physiological and behavioural functions is not limited to the intra-uterine or neonatal period. For example, recent studies show that adolescence and puberty, as well as adulthood, represent permissive windows for programming by stress (Lupien et al. 2009, Beardslee et al. 2012, Hunter \& McEwen 2013) and nutritional status (Pervanidou \& Chrousos 2012) in rodents and non-human primates. Conditions such as stress and obesity, on the one hand, and obesity and mental well-being, on the other, appear to be interdependent (Dauncey 2013, Sinha \& Jastreboff 2013); accordingly, it will be interesting to tease apart the contribution of the individual stimuli to the programming of physiology and behaviour. Other open questions concern how social history and the social context in which exposure occurs factor into the complex equation that defines phenotype, in particular psychopathological phenotypes (see Rutter 2012), and the mechanisms through which epigenetic programs are apparently transmitted across generations (Bohacek et al. 2012). Recently, Keverne (2013) suggested that the mechanisms that predispose an individual to epigenetic changes, rather than parental adaptations, can be transferred to subsequent generations (cf. Niwa et al. 2013).

\section{Adverse lifetime events and mental health}

Developmental psychobiologists have long been interested in the 'Nature vs. Nurture' question (for a comprehensive review, see Sameroff 2010). This area has recently generated much interest in psychiatry and neurology with growing recognition that historical (lifetime) events can have an impact on the etiopathogenesis of mood, affective and cognitive disorders (Tsankova et al. 2007, Lupien et al. 2009). For instance, trauma during childhood correlates with risk of developing anxiety and major depression in adulthood (Heim \& Binder 2012), and parent-infant relationships are reflected in executive functioning (Bernier et al. 2010, Hedges \& Woon 2011); similarly, early life adversity is associated with significant cognitive and emotional impairments in mice (Murgatroyd et al. 2009, Meaney 2010).

The above observations illustrate that brain health, like somatic health (Gluckman \& Hanson 2004, Wells 
2007, Hanson \& Gluckman 2011), is subject to adaptive programming induced by environmental cues. Notably, an authoritative policy paper observed that the 'mental wealth of nations' can be potentially improved by considering improvements in the social, economic health and educational environment that individuals are exposed to over the whole lifespan (Beddington et al. 2008), findings echoed in other studies (Duncan et al. 2010, Santos et al. 2012). Further, it is important to note that lifetime events do not necessarily leave an irreversible imprint on the brain. This is particularly well exemplified by research from the Bucharest Early Intervention Project (www. bucharestearlyinterventionproject.org/), which shows that foster care can, at least partially, reverse impairments in brain activity and cognition suffered by orphaned children (Smyke et al. 2010, Vanderwert et al. 2010, Fox et al. 2011, Sheridan et al. 2012, also see Rutter \& O’Connor 2004). Moreover, our own studies have shown spontaneous recovery from stressinduced neuromorphological and behavioural changes in the rat brain (Sousa \& Almeida 2012) and pharmacological correction of early life stress (ELS)-induced alterations in neuroendocrine, emotional and cognitive impairments in mice (Murgatroyd et al. 2009). The ability to effectively alter environment-triggered alterations in brain structure and function most likely depends on the quality, magnitude and duration of the initial 'insult' as well as on the exploitation of critical 'windows of interventional opportunity'.

The present review focuses on the epigenetic regulation of gene expression by ELS and its role in establishing neuroendocrine and behavioural phenotypes relevant to neuropsychiatric conditions. There are now strong links between stress (acute and accumulated) and disorders of cognition, mood and affect (Holsboer \& Ising 2010, Sousa \& Almeida 2012), and drug and alcohol abuse (Rodrigues et al. 2011); further, stress (and depression) is thought to predispose individuals to Alzheimer's disease (Sotiropoulos et al. 2011). In addition, stress is causally linked to metabolic disorders, such as overweight, obesity and diabetes (Noll et al. 2007, Scott et al. 2008, Kivimäki et al. 2011); on the one hand, these conditions are considered to be important risk factors for disturbances in mood, affect and cognition (Noll et al. 2007, Scott et al. 2008, Xu et al. 2011), and on the other hand, they may influence the efficacy of pharmacotherapies for certain brain disorders (Kloiber et al. 2007). Some of the best illustrations of how lifelong energy homoeostasis and susceptibility to metabolic and cardiac disease are programmed by the intra-uterine environment and comes from studies on foetal nutrition (Kyle \& Pichard 2006, Wells 2007, Gluckman 2011, Lillycrop \& Burdge 2011).
Increased glucocorticoid (GC) secretion is a key physiological response to stress. This response normally serves to restore physiological and behavioural homoeostasis through actions in a variety of cells, tissues and organs, including the brain. As their name implies, a major role of GC is to regulate energy (glucose) mobilization with concomitant increases in insulin secretion during stressful periods; their contribution to the adaptive response to stress includes suppression of immune and reproductive functions and increased cardiac output and blood supply to essential central and peripheral tissues (Selye 1998), as well as a diverse set of behavioural changes (e.g. hyperarousal and recall of contextual memories). However, the adaptation-promoting actions of GC can become deleterious for the organism when the regulatory mechanisms that operate to eventually restrain GC secretion go awry, especially when the type, strength or duration of the stressor exceeds certain thresholds.

Persistent GC hypersecretion may be considered as 'malprogramming' insofar that the rheostatic mechanisms that regulate the quality and magnitude of neuroendocrine responses (and subsequently, physiological, metabolic and behavioural responses) become dysregulated and compromise health and future adaptation. Excess GC levels in adults have been linked to major depression and anxiety (Holsboer \& Ising 2010) and a variety of other psychiatric, metabolic and immune disorders (Chrousos \& Kino 2007, Aguilera 2011); in addition, high levels of GC are associated with impairments in certain cognitive domains (Marin et al. 2011). Interestingly, both the mood- and cognition-impairing effects of GC in humans have been shown to be (at least transiently) reversible after correction of the underlying endocrine anomalies (Hook et al. 2007, Schatzberg \& Lindley 2008). While the ability of GC to alter adult brain architecture and connectivity in humans and experimental animals (Marin et al. 2011, Sousa \& Almeida 2012) is established, the influence of adverse early life experiences (and early life exposure to GC) on lifelong dysregulation of behavioural and GC secretion has only relatively recently become a major area of research.

\section{Prenatal stress and GC exposure}

Being small, lipophilic molecules, GC can readily traverse the placental barrier and influence brain development in utero, placing the foetuses of stressed mothers at special risk. Also at risk, are the offspring of women at risk of premature delivery because these subjects often receive GC therapy to accelerate maturation of the foetal lung (Hallman et al. 2010). The 
placenta has its own protective mechanism to reduce GC load on the foetus; it expresses high levels of the enzyme $11 \beta$-hydroxysteroid dehydrogenase 2 (11 $\beta$-HSD2), which converts active endogenous GC (cortisol and corticosterone) into inactive metabolites (cortisone and $11 \beta$-dehydrocorticosterone) that cannot activate glucocorticoid receptors (GR; Wyrwoll et al. 2011) (synthetic GCs, such as dexamethasone, that are used for therapeutic purposes are, however, not $11 \beta$-HSD2 substrates). Interestingly, $11 \beta$-HSD2 is also expressed in the brain, including areas involved in the control of emotion and cognition (Wyrwoll et al. 2011), thus serving as an additional protective gate against elevated GC levels.

The brain programming potential of prenatal GC exposure was recently reviewed by us (Mesquita et al. 2009, Rodrigues et al. 2011). We previously showed that treatment of rat dams with dexamethasone during the last trimester of pregnancy results in offspring that have a marked anxious phenotype (Oliveira et al. 2006). We also found that intra-uterine exposure to dexamethasone reduces the number of dopamine-producing cells and dopaminergic tone in the mesolimbic (ventral tegmentum-nucleus accumbens, VTA-NAc) reward pathway, with a significant reduction in the volume of NAc dendrites (Leão et al. 2007). Behavioural correlates of these neuromorphochemical changes were subsequently found: antenatal dexamethasone-treated animals displayed greater sensitivity to the psychostimulatory actions of the opiate morphine and increased preference for alcohol and morphine (drug-seeking phenotype) when tested as adults (Rodrigues et al. 2012). Molecular analyses carried out in the same study identified an epigenetic basis for these observations. Specifically, they revealed that prenatal dexamethasone leads to abnormal methylation of regulatory regions of the gene encoding the dopamine receptor (Drd2) and increased mRNA levels of Drd2 in the NAc. The latter was down-regulated after repeated administration of morphine, with parallel increases in methylation of the $\operatorname{Drd} 2$ promoter. Further, administration of L-DOPA, a substrate for dopamine synthesis, normalized the hypodopaminergic state, methylation of the $\operatorname{Drd} 2$ promoter, restored dendritic arborization in the NAc and reversed the drug-seeking behaviour shown by these animals. These findings show how GC pharmacotherapy in early life programs a particular behaviour (drug-seeking), a condition that frequently accompanies mood and affective disorders in humans.

The question of how prenatal stress or GC accesses the brain was recently addressed in an important paper, which showed that restraint stress during pregnancy in rats leads to concomitant decreases in placental expression of $11 \beta-\mathrm{Hsd} 2$ (associated with increased DNA methylation at specific $\mathrm{CpG}$ sites within the HSD11b2 promoter) and increases in DNA methyltransferase 3a mRNA (Jensen Peña et al. 2012). In humans, maternal GC levels correlate with those found in the foetus (Gitau et al. 1998), indicating that the placental barrier can be breached with implications for the development of psychopathology in the offspring. A recent study reported heightened endocrine responses to stress and depressive-like behaviour in the male offspring of mouse dams that experienced stress during early gestation (before the presence of a foetal brain); this phenotype was characterized by increased expression of the gene encoding corticotrophin-releasing hormone (Crh, a neuropeptide responsible for driving GC secretion), correlating with reduced methylation of the Crh promoter (Mueller \& Bale 2008). Jensen Peña et al. (2012) noted that maladaptive behaviours in the offspring of mothers experiencing high GC levels during pregnancy may be viewed as the cost of survival. At this juncture, it deserves mention that, as Seymour Levine, a pioneer of this aspect of developmental psychobiology, observed, certain stress paradigms may actually evoke 'positive' effects (Levine 1957). For example, mild GC elevations during prenatal and neonatal life in rodents improve cognition and emotional responses (Catalani et al. 2011) and may facilitate adaptive adjustments to future challenges (Macrì et al. 2011). These ideas may be fundamental to understanding the origins of individual differences in resisting stress-related psychological and somatic disease (see Levine 2005).

\section{Early postnatal programming}

Primates and rodents are altricial species, so survival of their young depends on parental (usually, maternal) provision of nutrients and water, hygiene/grooming, warmth and protection from other inclement environmental factors, including predators. Neglect during childhood is known to have detrimental effects on overall neurodevelopment and brain structure (Kaufman \& Charney 2001, Hedges \& Woon 2011, Cisler et al. 2013) and is strongly associated with psychiatric disorders such as depression, post-traumatic disorder and schizophrenia (Morgan \& Fisher 2007, Heim \& Binder 2012). A series of pioneering studies in rats by Michael Meaney's group reported that the offspring of dams showing higher levels of maternal care (licking and grooming) develop into adults with lower endocrine (GC) responses to stress, as compared to the offspring of mothers that display less intense maternal behaviour (for review, see Zhang et al. 2013). The former offspring also showed higher levels of expression of hippocampal GR and, subsequently, faster 'shut off' of the endocrine response to stress and reduced hypothalamic 
Crh mRNA expression, both reflecting superior GC negative feedback regulation. Cross-fostering studies suggested that epigenetic mechanisms might be responsible for the observed phenotype, a view upheld by the discovery of differential histone acetylation and DNA methylation of a specific exon in the GR promoter in the hippocampi of offspring of high vs. low maternal caregivers. The potential translational importance of these findings is reflected in another finding from the Meaney laboratory, which reported that suicide victims who had experienced childhood abuse express low hippocampal levels of GR mRNA in association with increased methylation of the GR promoter (McGowan et al. 2009).

Our laboratory employs a different ELS paradigm in mice (C57/Bl6n strain) in an attempt to understand the relationship between stress and psychopathology from an epigenetic perspective (Murgatroyd et al. 2009). Our ELS protocol involves daily separation ( $3 \mathrm{~h}$, variable times of the day) of mouse litters from their dams during the first ten postnatal days, leading to characteristic endocrine and behavioural phenotypes in adulthood. Specifically, male ELS-exposed mice display learned helplessness (immobility) in the forced swim test and impaired spatial and fear-conditioned learning. At the same time, ELS-treated mice have elevated GC levels under baseline conditions and show stress-induced GC secretory responses that are exaggerated in terms of magnitude and duration (indicating impaired GC negative feedback in the brain and pituitary and/or hyperactivation of the hypothalamic neurones responsible for positive regulation of GC secretion). Following a candidate gene approach, we searched for epigenetic modifications in a number of genes in the limbic-hypothalamic-pituitary circuitry that are known to be important for regulation of GC secretion. Among others, this analysis revealed hypomethylation of the so-called enhancer region of $A v p$, the gene that encodes arginine vasopressin (Avp), a hypothalamic neuropeptide that, under sustained demand (e.g. chronic stress or adrenalectomy), plays a critical role in ensuring higher corticotrope-GC output (Tilders et al. 1985, Davis et al. 1986, Hellbach et al. 1998). Consistent with our demonstration that this hypomethylation resulted in attenuated binding of methyl CpG-binding protein 2 (Mecp2) to the Avp enhancer (Mecp2 serves as a scaffold for the assembly of repressor complexes including histone deacetylases and DNA methyltransferases), we observed an up-regulation of Avp mRNA expression (Murgatroyd et al. 2009). Further analysis revealed that ELS-induced DNA hypomethylation is preceded by loss of Mecp2 occupancy during early life; the latter event depends on activity-driven phosphorylation of Mecp2 through the mediation of
$\mathrm{Ca}^{2+}$-/calmodulin-dependent protein kinase II (CaMKII). The observation that loss of Mecp2 occupancy requires neural activity is important: it dismisses a role for GC in the mechanisms leading to hypomethylation of the Avp enhancer. In fact, the rodent adrenal first produces detectable levels of GC from about postnatal day 14; until this age, rodents are considered to be 'stress-hyporesponsive' (Sapolsky \& Meaney 1986) even though they can emit ultrasonic calls (Hofer 1996) and release catecholamines (Sullivan 2003) from birth.

The above-reported molecular and endocrine responses induced by ELS were first seen at day 10 of life (at the end of the ELS paradigm) and were detectable for at least 1 year (Murgatroyd et al. 2009). Without necessarily excluding other mechanisms, these sustained changes in endocrine and behavioural function can be largely attributed to ELS-induced modifications in Avp expression because the phenotype was reversible with an AVP receptor antagonist (Murgatroyd et al. 2009). Another interesting aspect of this study is that the epigenetic changes observed occurred in (presumably) postmitotic neurones; although neurogenesis has been described in certain hypothalamic nuclei, the parvocellular paraventricular nucleus, in which the AVP neurones of interest to this work are located, is not known to be a neuroproliferative zone.

\section{The peripubertal window - adolescent obesity and adult behaviour}

Body mass and adiposity in childhood and adolescence appear to be good predictors of risk of obesity in adulthood. Comorbidity of adult overweight and depression and anxiety disorders occurs frequently (especially among women), with clinical evidence pointing to bilateral interactions between weight and mood/emotional states during adolescence and adulthood (Heo et al. 2006, Noll et al. 2007, Strine et al. 2008, Wouters et al. 2011). A number of interacting intra- and interdomain factors are likely to contribute to the final behavioural and metabolic phenotype, including psychological (e.g. family/social stability, self-esteem, dissatisfaction with body image, stigmatization, role models, motivation, behavioural control), physiological (e.g. multiple endocrine factors, including insulin, leptin, GC, sex steroids; energy absorption and utilization) and environmental (e.g. peer pressure, promotional media, physical activity, socio-economic circumstances) (Bornstein et al. 2006, Hyde et al. 2008, Cole et al. 2012). While body mass and adiposity are determined by the amount of energy consumed and the amount of energy expended, it is interesting that depression becomes more prevalent in girls than 
in boys around the onset of puberty (Cyranowski et al. 2000, Angold \& Costello 2006).

In a recent (unpublished) study, we examined how transient diet-induced obesity (DIO) in peripubertal rats influences adult behaviour in male and female rats (from between days 21 and days 80 of life, with testing when rats were 180 days old; see Fig. 1). Our experimental design was chosen against the background that reward (here delivered in the form of a palatable cafeteria-type diet) and mood are closely linked (Scott et al. 2008, Kivimäki et al. 2011, Dauncey 2013, Sinha \& Jastreboff 2013), with both being subject to modulation by peripheral endocrine and metabolic signals. The paradigm used to achieve DIO involved giving animals a choice between standard chow and cafeteria diet (CD) that changed on a daily basis. While the use of CD in rodent experiments has certain advantages over HFD (Sampey et al. 2011), the CD approach is limited by the fact that the experimenter does not have complete control of the composition (individual ingredients and energy) of the food. To increase palatability of the $\mathrm{CD}$, investigators commonly use foods that contain animal fat products or chocolate; we however avoided such foods for ethical reasons as well as hygiene and reproducibility and instead increased the incentive salience of the CD by providing chocolate-free diets containing nuts, marzipan, fruit-flavoured cereal bars and shortbread. Control animals only received standard chow.

Animals consumed high amounts of the CD, but they nevertheless continued to consume small amounts of the standard chow and showed rapid body weight gain, when compared to age-matched controls (Fig. 2a). Interestingly, when the $\mathrm{CD}$ was withdrawn at the age of 80 days, female rats showed reduced BW gain, whereas male rats continued to show body weight increases above those seen in agematched control animals (Fig. 2b). Consistent with these feeding and growth patterns, CD-exposed males were found to have larger fat pads at necropsy (Fig. 2c).
Behavioural phenotyping (see Sousa et al. 2006 for methodological background) performed when animals were approx. 180 days old (100 days after last exposure to $\mathrm{CD}$ ) revealed that the peripubertal DIO paradigm led to alterations in anxiety- and depression-like behaviour. Both males and females that had been exposed to the CD during peripubertal life displayed stronger signs of depression-like behaviour when tested in the forced swim test (Fig. 3a). Depression and anxiety frequently co-exist in humans, with greater comorbidity occurring in women (Alexander et al. 2007). We here observed, however, that whereas CD-exposed males were significantly more anxious than their age-matched controls in two different behavioural assays (open arena and an elevated plus maze), CD-exposed females were, if anything, less anxious than their corresponding controls (Fig. 3b).

As mentioned earlier, there are strong correlations between stress, GC levels and mood and emotional behaviour (Holsboer \& Ising 2010). In view of this, we also examined GC levels in control and CD-exposed rats at the age of 180 days. Surprisingly, no differences were observed in daytime (nadir) and night-time (peak) GC levels when control and CD-treated male rats were compared (Fig. 4a). As expected, control female rats displayed higher levels of GC secretion than males (both time points) (Fig. 4a). Daytime and night-time GC levels were significantly higher in CD-exposed females as compared to their corresponding standard diet-fed controls (Fig. 4a). The latter results were supported by measures of GR mRNA expression in the hippocampus, a key brain area involved in the mediation of GC negative feedback: as shown in Figure 4b, the CD-exposed females were the only group to exhibit any treatmentrelated changes (decreases) in hippocampal $G R$ expression. Lastly, the female CD-treated rats stood out from among the other experimental groups in that they showed the largest GC secretory response to an acute stressor (at $30 \mathrm{~min}$ ). The above-reported data suggest that CD exposure during peripubertal

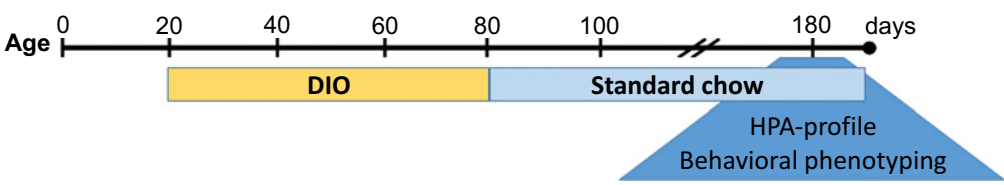

Figure I Experimental protocol used to examine the influence of diet-induced obesity (DIO) on activity of the hypothalamopituitary-adrenal (HPA) axis and depression-like and anxiety-related behaviour in rats. Male and female Wistar rats were weaned on postnatal day 21 and maintained under standard laboratory conditions. Animals were provided ad libitum with either standard laboratory chow (controls) or a cafeteria diet (CD) from days 21 to 80 of life to induce peripubertal DIO (ppDIO). From day 80 onwards, all animals were kept on standard laboratory chow. On postnatal day 180 (100 days after withdrawal of the CD), animals were successively tested for anxiety-related and depression-like behaviours (using the elevated plus maze test and forced swim test, respectively) and HPA axis activity under basal and acute stress (2-min air puff) conditions. There was an interval of 1 week between each of the tests. 

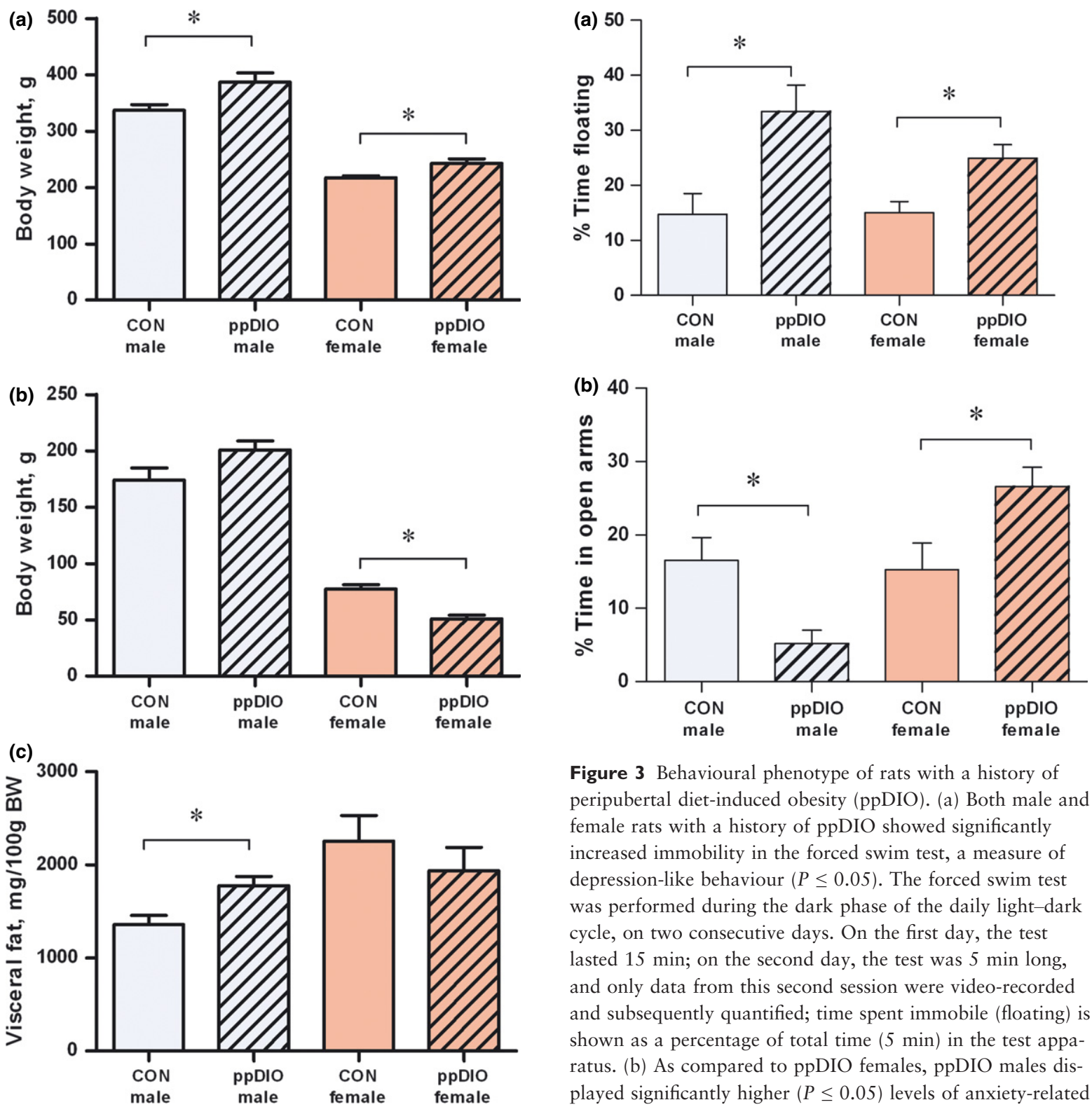

Figure 2 Body weight changes and visceral fat mass. (a) Male and female rats with access to cafeteria diet (ppDIO) from days 21 to 80 of life displayed gained body weight gains that were significantly greater than chow-fed controls $(P \leq 0.05)$. (b) A small (non-significant) increase in body weight was observed in ppDIO males that were returned to standard chow between the ages of 80 and 180 days; in contrast, similarly treated females showed a small but significant slowdown of weight gain $(P \leq 0.05)$. (c) Although ppDIO males that were returned to standard chow between the ages of 80 and 180 did not show weight gain, they displayed a significantly higher mass of visceral fat $(P \leq 0.05)$. All values shown are mean $\pm \operatorname{SEM}(n=5-7$ per group). Asterisks indicate $P<0.05$ ( $t$-test comparisons of samesex groups). ppDIO, peripubertal diet-induced obesity.

development leads to sex-specific disruption of the normal processes regulating GC secretion under basal and stressful conditions and a dissociation of GC

Figure 3 Behavioural phenotype of rats with a history of peripubertal diet-induced obesity (ppDIO). (a) Both male and female rats with a history of ppDIO showed significantly increased immobility in the forced swim test, a measure of depression-like behaviour $(P \leq 0.05)$. The forced swim test was performed during the dark phase of the daily light-dark cycle, on two consecutive days. On the first day, the test lasted $15 \mathrm{~min}$; on the second day, the test was $5 \mathrm{~min}$ long, and only data from this second session were video-recorded and subsequently quantified; time spent immobile (floating) is shown as a percentage of total time $(5 \mathrm{~min})$ in the test apparatus. (b) As compared to ppDIO females, ppDIO males displayed significantly higher $(P \leq 0.05)$ levels of anxiety-related behaviour in the elevated plus maze (EPM), as measured by the percentage of time they spent exploring the open arms of the maze. Data shown are mean \pm SEM ( $n=5-7$ per group). Asterisks indicate $P<0.05$ ( $t$-test comparisons of same-sex groups).

secretory levels from the expression of depression- and anxiety-like behaviours.

\section{Back to the future}

Life events clearly influence physiological and behavioural trajectories. As reviewed here, early life experiences exert their effects, at least in part, through epigenetic mechanisms that lead to long-term changes in gene expression potential and, as has been recognized for decades, the brain is accessible to environment-induced 
plasticity from very early gestation through to puberty. Obviously, much still remains to be done in order to identify those external stimuli that have the greatest impact on any given function of interest, as well as to assess to what extent that stimulus alters quality of life.

Survival is ensured by dynamic adaptations at the multilayered levels of organization and regulation of physiological processes; it will be therefore important to know the extent of 'permanency' of the snapshot phenotypes that we and others have recorded to date. Growing acceptance of the view that even DNA methylation may not result in indelible epigenetic marks

(a)
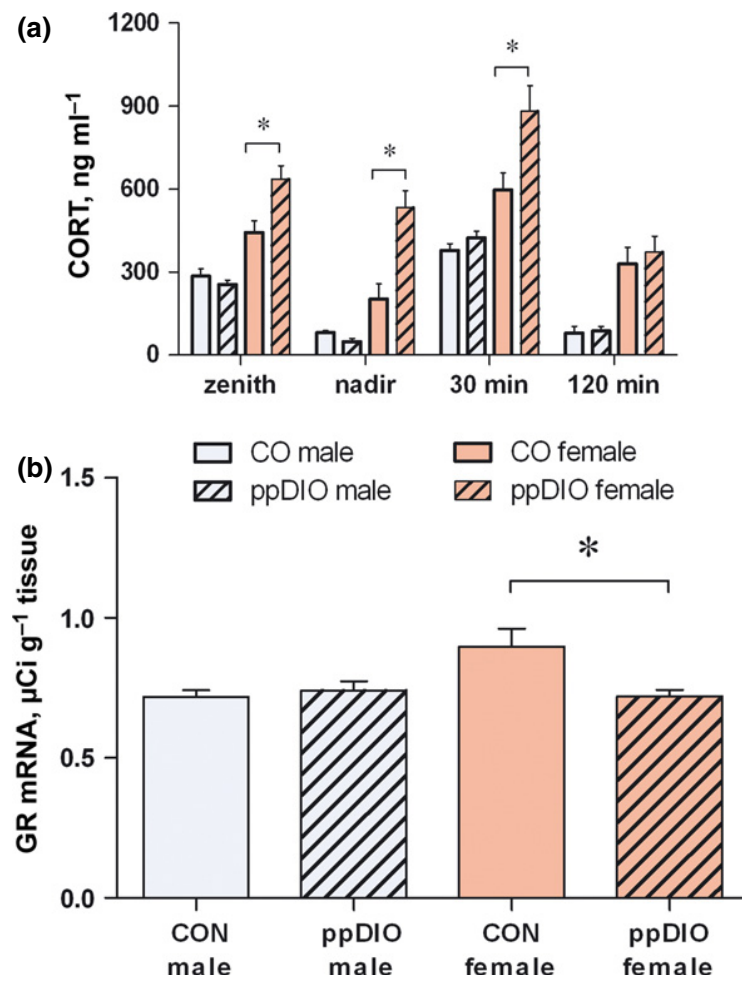

Figure 4 Peripubertal diet-induced obesity (ppDIO) effects on regulation of hypothalamo-pituitary-adrenal (HPA) axis activity. (a) Activity of the HPA axis was assessed under basal (resting) conditions during the daily zenith and nadir of corticosterone (CORT) secretion, as well as 30 or $120 \mathrm{~min}$ after exposure to an acute (air puff) stressor. Serum CORT was measured using a commercial radioimmunoassay kit (MP Biochemicals, Costa Mesa, CA, USA). Data show that ppDIO blunts the circadian fluctuations in HPA axis activity in female, but not in male, rats $(P \leq 0.05)$. Further, ppDIO rats showed an exaggerated response to acute stress. (b) Shows results of semiquantitative in situ hybridization analysis of glucocorticoid receptor (GR) mRNA expression in the dentate gyrus of the hippocampal formation. There was a significant down-regulation of GR mRNA in ppDIO females $(P \leq 0.05)$. All data are shown mean $\pm \operatorname{SEM}(n=5-7$ per group). Asterisks indicate $P<0.05$ ( $t$-test comparisons of same-sex groups).
(Métivier et al. 2008, Ma et al. 2009, Lee et al. 2010, Guo et al. 2011a,b, Unternaehrer et al. 2012) prompts the question of how different signals arriving at intervals over lifetime act on the pre-existing epigenome to (re)shape the next phase of life. This necessarily includes definition of the spectrum of windows that may be accessible to epigenetic modification; it may be too early to exclude that these can open, narrow, close and even re-open in cell-, network- and environment-specific ways (Fig. 5). Keeping an open mind to these possibilities will not only help physiologists to appreciate the full potential of the brain's plasticity but may also provide biological explanations for how otherwise fixed programs become reversible through social, psychological and pharmacological interventions, some examples of which were given earlier in this article.

Epigenetic mechanisms bring a promising and exciting new perspective to the physiologist's quest to comprehend the complex systems as well as their integration that result in coordinated responses to internal and external demands. Remembering Leonardo da

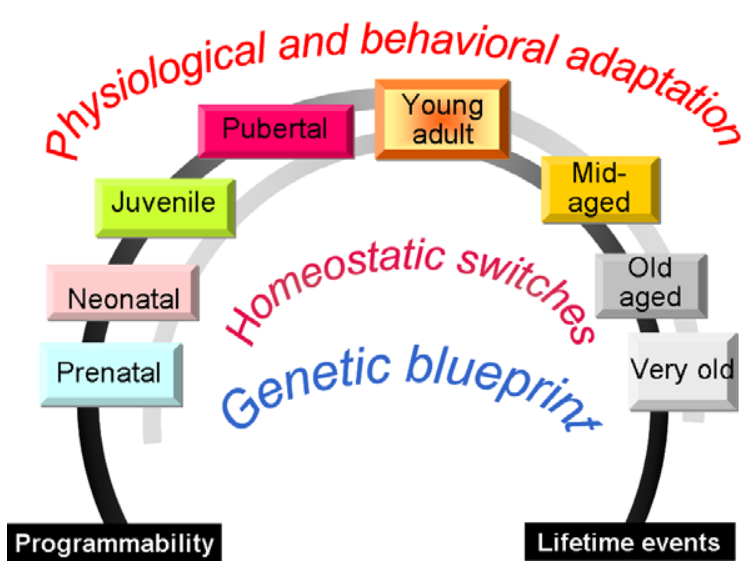

Figure 5 Maintenance of physiological and behavioural homoeostasis during different phases of the lifespan. Lifetime events (e.g. stress, altered nutrition) can act directly (and rapidly) on genetically determined physiological switches, but may also induce epigenetic changes in varying degrees of permanency (not shown). As indicated by the decreasing intensity of shading of the 'programmability' curve, from prenatal to very old ages, it is thought that the brain of young individuals is more amenable to programming (epigenetic or otherwise) than that of older individuals. The schema shows that older subjects will have experienced more life events (positive and negative; note the increasing shading intensity of the 'lifetime events' curve, from prenatal to very old ages) that will serve as a 'reference library' for responding to future demands. This cumulative experience, 'archived' in previously adjusted physiological switches or epigenetic modifications, will play a decisive role in whether a subject ages healthily or unhealthily. 
Vinci's adage 'Simplicity is the ultimate sophistication' may be useful in designing future experiments to examine gene $\times$ environment interactions in the context of behavioural or psychiatric disorders; by definition, these disorders are complex as they involve interplay between different neural networks that are themselves subject to local regulation and modulation. Standardizing animal models and molecular and phenotypic analyses and being aware that a behaviour is unlikely to depend on a single gene or brain region may help us reach our goal more effectively. Moreover, biomedical experimentalists need to exert more care in extrapolating findings in model organisms to humans. As recently demonstrated in the context of modelling human psychiatric disease in animals, the impact of a given environmental stimulus may depend heavily upon predisposing genetic risks (Niwa et al. 2013). Interpretation of many of the animal studies discussed in this article is based on anthropomorphism; thus, extrapolations from experiments in animal models of disease to psychopathological conditions in humans require a certain degree of caution (see Seok et al. 2013). On the other hand, given that many molecular pathways and mechanisms are conserved across species, animal research undoubtedly serves to advance our understanding of complex behaviours, with further advances expected as investigators refine their models. Moreover, although developments in computational neuroscience and sophisticated minimally invasive neurotechnologies will facilitate exploration of the intricate circuitries that regulate human behaviour, the molecular dissection of normal and pathological human behaviour remains a long shot, not least because of safety and ethical considerations.

\section{Conflict of interest}

None of the authors have any conflict of interests to declare. The funding agency did not have any influence over the conception, design, interpretation or writing of this article or over the authors' unpublished data described in this article.

Work reported from the authors' laboratories was supported by European Union-funded projects CRESCENDO (FP6 Integrated Project 018652 to OFXA and DS) and SWITCHBOX (FP 7 Integrated Project 259772 to OFXA and NS). OFXA and DS were supported by the Max Planck Institute of Psychiatry and thank Professor Florian Holsboer for encouraging this work.

\section{References}

Aguilera, G. 2011. HPA axis responsiveness to stress: implications for healthy aging. Exp Gerontol 46, 90-95.
Alexander, J.L., Dennerstein, L., Kotz, K. \& Richardson, G. 2007. Women, anxiety and mood: a review of nomenclature, comorbidity and epidemiology. Expert Rev Neurother 7(11 Suppl), S45-S58.

Angold, A. \& Costello, E.J. 2006. Puberty and depression. Child Adolesc Psychiatr Clin N Am 15, 919-937.

Baker-Andresen, D., Ratnu, V.S. \& Bredy, T.W. 2013. Dynamic DNA methylation: a prime candidate for genomic metaplasticity and behavioral adaptation. Trends Neurosci 36, 3-13.

Beardslee, W.R., Gladstone, T.R. \& O'Connor, E.E. 2012. Developmental risk of depression: experience matters. Child Adolesc Psychiatr Clin N Am 21, 261-278.

Beddington, J., Cooper, C.L., Field, J., Goswami, U., Huppert, F.A., Jenkins, R., Jones, H.S., Kirkwood, T.B., Sahakian, B.J. \& Thomas, S.M. 2008. The mental wealth of nations. Nature 455, 1057-1060.

Bernier, A., Carlson, S.M., Bordeleau, S. \& Carrier, J. 2010. Relations between physiological and cognitive regulatory systems: infant sleep regulation and subsequent executive functioning. Child Dev 81, 1739-1752.

Bohacek, J., Gapp, K., Saab, B.J. \& Mansuy, I.M. 2012. Transgenerational epigenetic effects on brain functions. Biol Psychiatry 73, 313-320.

Bornstein, S.R., Schuppenies, A., Wong, M.L. \& Licinio, J. 2006. Approaching the shared biology of obesity and depression: the stress axis as the locus of gene-environment interactions. Mol Psychiatry 11, 892-902.

Bourgeois, J.P. 1997. Synaptogenesis, heterochrony and epigenesis in the mammalian neocortex. Acta Paediatr Suppl 422, 27-33.

Castrén, E. \& Hen, R. 2013. Neuronal plasticity and antidepressant actions. Trends Neurosci 36, 259-267.

Catalani, A., Alemà, G.S., Cinque, C., Zuena, A.R. \& Casolini, P. 2011. Maternal corticosterone effects on hypothalamuspituitary-adrenal axis regulation and behavior of the offspring in rodents. Neurosci Biobehav Rev 35, 1502-1517.

Chrousos, G.P. \& Kino, T. 2007. Glucocorticoid action networks and complex psychiatric and/or somatic disorders. Stress 10, 213-219.

Cisler, J.M., James, G.A., Tripathi, S., Mletzko, T., Heim, C., Hu, X.P., Mayberg, H.S., Nemeroff, C.B. \& Kilts, C.D. 2013. Differential functional connectivity within an emotion regulation neural network among individuals resilient and susceptible to the depressogenic effects of early life stress. Psychol Med 43, 507-518.

Cole, D.A., Cho, S.J., Martin, N.C., Youngstrom, E.A., March, J.S., Findling, R.L., Compas, B.E., Goodyer, I.M., Rohde, P., Weissman, M. et al. 2012. Are increased weight and appetite useful indicators of depression in children and adolescents? J Abnorm Psychol 121, 838-851.

Cowan, W.M. 1979. The development of the brain. Sci Am 241, 113-133.

Cyranowski, J.M., Frank, E., Young, E. \& Shear, M.K. 2000. Adolescent onset of the gender difference in lifetime rates of major depression: a theoretical model. Arch Gen Psychiatry 57, 21-27.

Dauncey, M.J. 2013. Recent advances in nutrition, genes and brain health. Proc Nutr Soc 71, 581-591. 
Davis, L.G., Arentzen, R., Reid, J.M., Manning, R.W., Wolfson, B., Lawrence, K.L. \& Baldino, F. Jr 1986. Glucocorticoid sensitivity of vasopressin mRNA levels in the paraventricular nucleus of the rat. Proc Natl Acad Sci 83, $1145-1149$

Duncan, G.J., Ziol-Guest, K.M. \& Kalil, A. 2010. Earlychildhood poverty and adult attainment, behavior, and health. Child Dev 81, 306-325.

Eriksson, P.S., Perfilieva, E., Björk-Eriksson, T., Alborn, A.M., Nordborg, C., Peterson, D.A. \& Gage, F.H. 1998. Neurogenesis in the adult human hippocampus. Nat Med 4, 1313-1317.

Fox, N.A., Almas, A.N., Degnan, K.A., Nelson, C.A. \& Zeanah, C.H. 2011. The effects of severe psychosocial deprivation and foster care intervention on cognitive development at 8 years of age: findings from the Bucharest Early Intervention Project. J Child Psychol Psychiatry 52, 919-928.

Gao, W., Gilmorem, J.H., Giovanellom, K.S., Smith, J.K., Shen, D., Zhu, H. \& Lin, W. 2011. Temporal and spatial evolution of brain network topology during the first two years of life. PLOS ONE 6, e25278.

Gitau, R., Cameron, A., Fisk, N.M. \& Glover, V. 1998. Fetal exposure to maternal cortisol. Lancet 352, 707-708.

Gluckman, P.D. 2011. Epigenetics and metabolism in 2011: epigenetics, the life-course and metabolic disease. Nat Rev Endocrinol 8, 74-76.

Gluckman, P.D. \& Hanson, M.A. 2004. Living with the past: evolution, development, and patterns of disease. Science 305, 1733-1736.

Griffith, J.S. \& Mahler, H.R. 1969. DNA ticketing theory of memory. Nature 223, 580-582.

Guo, J.U., Ma, D.K., Mo, H., Ball, M.P., Jang, M.H., Bonaguidi, M.A., Balazer, J.A., Eaves, H.L., Xie, B., Ford, E., Zhang, K., Ming, G.L., Gao, Y. \& Song, H. 2011a. Neuronal activity modifies the DNA methylation landscape in the adult brain. Nat Neurosci 14, 1345-1351.

Guo, J.U., Su, Y., Zhong, C., Ming, G.L. \& Song, H. 2011b. Hydroxylation of 5-methylcytosine by TET1 promotes active DNA demethylation in the adult brain. Cell 145, 423-434.

Hallman, M., Peltoniemi, O. \& Kari, M.A. 2010. Enhancing functional maturity before preterm birth. Neonatology 97, 373-378.

Hanson, M. \& Gluckman, P. 2011. Developmental origins of noncommunicable disease: population and public health implications. Am J Clin Nutr 94(Suppl 6), 1754S-1758S.

Hedges, D.W. \& Woon, F.L. 2011. Early-life stress and cognitive outcome. Psychopharmacology 214, 121-130.

Heim, C. \& Binder, E.B. 2012. Current research trends in early life stress and depression: review of human studies on sensitive periods, gene-environment interactions, and epigenetics. Exp Neurol 233, 102-111.

Hellbach, S., Gärtner, P., Deicke, J., Fischer, D., Hassan, A.H. \& Almeida, O.F.X. 1998. Inherent glucocorticoid response potential of isolated hypothalamic neuroendocrine neurons. FASEB J 12, 199-207.

Heo, M., Pietrobelli, A., Fontaine, K.R., Sirey, J.A. \& Faith, M.S. 2006. Depressive mood and obesity in US adults: comparison and moderation by sex, age, and race. Int $J$ Obes (Lond) 30, 513-519.

Hofer, M.A. 1996. Multiple regulators of ultrasonic vocalization in the infant rat. Psychoneuroendocrinology 21, 203217.

Hoffmann, A. \& Spengler, D. 2012. The lasting legacy of social stress on the epigenome of the hypothalamic-pituitary-adrenal axis. Epigenomics 4, 431-444.

Holsboer, F. \& Ising, M. 2010. Stress hormone regulation: biological role and translation into therapy. Annu Rev Psychol 61, 81-109, C1-11.

Hook, J.N., Giordani, B., Schteingart, D.E., Guire, K., Giles, J., Ryan, K., Gebarski, S.S., Langenecker, S.A. \& Starkman, M.N. 2007. Patterns of cognitive change over time and relationship to age following successful treatment of Cushing's disease. J Int Neuropsychol Soc 13, 21-29.

Hunter, R.G. \& McEwen, B.S. 2013. Stress and anxiety across the lifespan: structural plasticity and epigenetic regulation. Epigenomics 5, 177-194.

Huttenlocher, P.R. \& Dabholkar, A.S. 1997. Regional differences in synaptogenesis in human cerebral cortex. J Comp Neurol 387, 167-178.

Hyde, J.S., Mezulis, A.H. \& Abramson, L.Y. 2008. The $\mathrm{ABCs}$ of depression: integrating affective, biological, and cognitive models to explain the emergence of the gender difference in depression. Psychol Rev 115, 291-313.

Jensen Peña, C., Monk, C. \& Champagne, F.A. 2012. Epigenetic effects of prenatal stress on $11 \beta$-hydroxysteroid dehydrogenase-2 in the placenta and fetal brain. PLOS ONE 7, e39791.

Jernigan, T.L., Baaré, W.F., Stiles, J. \& Madsen, K.S. 2011. Postnatal brain development: structural imaging of dynamic neurodevelopmental processes. Prog Brain Res 189, 77-92.

Kaufman, J. \& Charney, D. 2001. Effects of early stress on brain structure and function: implications for understanding the relationship between child maltreatment and depression. Dev Psychopathol 13, 451-471.

Kempermann, G. 2012. New neurons for 'survival of the fittest'. Nat Rev Neurosci 13, 727-736.

Keverne, E.B. 2013. Importance of the matriline for genomic imprinting, brain development and behaviour. Philos Trans R Soc Lond B Biol Sci 368, 20110327.

Kivimäki, M., Jokela, M., Hamer, M., Geddes, J., Ebmeier, K., Kumari, M., Singh-Manoux, A., Hingorani, A. \& Batty, G.D. 2011. Examining overweight and obesity as risk factors for common mental disorders using fat mass and obesity-associated (FTO)genotype-instrumented analysis: the Whitehall II Study, 1985-2004. Am J Epidemiol 173, 421-429.

Kloiber, S., Ising, M., Reppermund, S., Horstmann, S., Dose, T., Majer, M., Zihl, J., Pfister, H., Unschuld, P.G., Holsboer, F. \& Lucae, S. 2007. Overweight and obesity affect treatment response in major depression. Biol Psychiatry $62,321-326$.

Knickmeyer, R.C., Gouttard, S., Kang, C., Evans, D., Wilber, K., Smith, J.K., Hamer, R.M., Lin, W., Gerig, G. \& Gilmore, J.H. 2008. A structural MRI study of human brain development from birth to 2 years. J Neurosci 28, 12176-12182. 
Kyle, U.G. \& Pichard, C. 2006. The Dutch Famine of 1944 1945: a pathophysiological model of long-term consequences of wasting disease. Curr Opin Clin Nutr Metab Care 9, 388-394.

Leão, P., Sousa, J.C., Oliveira, M., Silva, R., Almeida, O.F.X. \& Sousa, N. 2007. Programming effects of antenatal dexamethasone in the developing mesolimbic pathways. Synapse 61, 40-49.

Lee, R.S., Tamashiro, K.L., Yang, X., Purcell, R.H., Harvey, A., Willour, V.L., Huo, Y., Rongione, M., Wand, G.S. \& Potash, J.B. 2010. Chronic corticosterone exposure increases expression and decreases deoxyribonucleic acid methylation of Fkbp5 in mice. Endocrinology 151, 43324343.

Levine, S. 1957. Infantile experience and resistance to physiological stress. Science 126, 405.

Levine, S. 2005. Developmental determinants of sensitivity and resistance to stress. Psychoneuroendocrinology 30, 939-946.

Levitt, P. 2003. Structural and functional maturation of the developing primate brain. J Pediatr 143(4 Suppl), S35-S45.

Lillycrop, K.A. \& Burdge, G.C. 2011. Epigenetic changes in early life and future risk of obesity. Int J Obes (Lond) 35, $72-83$.

Lupien, S.J., McEwen, B.S., Gunnar, M.R. \& Heim, C. 2009. Effects of stress throughout the lifespan on the brain, behaviour and cognition. Nat Rev Neurosci 10, 434-445.

Ma, D.K., Guo, J.U., Ming, G.L. \& Song, H. 2009. DNA excision repair proteins and Gadd45 as molecular players for active DNA demethylation. Cell Cycle 8, 1526-1531.

Ma, D.K., Marchetto, M.C., Guo, J.U., Ming, G.L., Gage, F.H. \& Song, H. 2010. Epigenetic choreographers of neurogenesis in the adult mammalian brain. Nat Neurosci 13, 1338-1344.

Macrì, S., Zoratto, F. \& Laviola, G. 2011. Early-stress regulates resilience, vulnerability and experimental validity in laboratory rodents through mother-offspring hormonal transfer. Neurosci Biobehav Rev 35, 1534-1543.

Marin, M.F., Lord, C., Andrews, J., Juster, R.P., Sindi, S., Arsenault-Lapierre, G., Fiocco, A.J. \& Lupien, S.J. 2011. Chronic stress, cognitive functioning and mental health. Neurobiol Learn Mem 96, 583-595.

Mateus-Pinheiro, A., Pinto, L., Bessa, J.M., Morais, M., Alves, N.D., Monteiro, S., Patrício, P., Almeida, O.F.X. \& Sousa, N. 2013. Sustained remission from depressive-like behavior depends on hippocampal neurogenesis. Transl Psychiatry 3, e210.

McGowan, P.O., Sasaki, A., D’Alessio, A.C., Dymov, S., Labonté, B., Szyf, M., Turecki, G. \& Meaney, M.J. 2009. Epigenetic regulation of the glucocorticoid receptor in human brain associates with childhood abuse. Nat Neurosci $12,342-348$.

Meaney, M.J. 2010. Epigenetics and the biological definition of gene $\times$ environment interactions. Child Dev 81, 41-79.

Mesquita, A.R., Wegerich, Y., Patchev, A.V., Oliveira, M., Leão, P., Sousa, N. \& Almeida, O.F.X. 2009. Glucocorticoids and neuro- and behavioural development. Semin Fetal Neonatal Med 14, 130-135.
Métivier, R., Gallais, R., Tiffoche, C., Le Péron, C., Jurkowska, R.Z., Carmouche, R.P., Ibberson, D., Barath, P., Demay, F., Reid, G., Benes, V., Jeltsch, A., Gannon, F. \& Salbert, G. 2008. Cyclical DNA methylation of a transcriptionally active promoter. Nature 452, 45-50.

Morgan, C. \& Fisher, H. 2007. Environment and schizophrenia: environmental factors in schizophrenia: childhood trauma-a critical review. Schizophr Bull 33, 3-10.

Mueller, B.R. \& Bale, T.L. 2008. Sex-specific programming of offspring emotionality after stress early in pregnancy. J Neurosci 28, 9055-9065.

Murgatroyd, C., Patchev, A.V., Wu, Y., Micale, V., Bockmühl, Y., Fischer, D., Holsboer, F., Wotjak, C.T., Almeida, O.F.X. \& Spengler, D. 2009. Dynamic DNA methylation programs persistent adverse effects of early-life stress. Nat Neurosci 12, 1559-1566.

Niwa, M., Jaaro-Peled, H., Tankou, S., Seshadri, S., Hikida, T., Matsumoto, Y., Cascella, N.G., Kano, S., Ozaki, N., Nabeshima, T. \& Sawa, A. 2013. Adolescent stressinduced epigenetic control of dopaminergic neurons via glucocorticoids. Science 339, 335-339.

Noll, J.G., Zeller, M.H., Trickett, P.K. \& Putnam, F.W. 2007. Obesity risk for female victims of childhood sexual abuse: a prospective study. Pediatrics 120, e61-e67.

Oliveira, M., Bessa, J.M., Mesquita, A., Tavares, H., Carvalho, A., Silva, R., Pêgo, J.M., Cerqueira, J.J., Palha, J.A., Almeida, O.F.X. \& Sousa, N. 2006. Induction of a hyperanxious state by antenatal dexamethasone: a case for less detrimental natural corticosteroids. Biol Psychiatry 59, 844-852.

Pervanidou, P. \& Chrousos, G.P. 2012. Metabolic consequences of stress during childhood and adolescence. Metabolism 61, 611-619.

Ptashne, M. 2013. Epigenetics: core misconcept. Proc Natl Acad Sci 110, 7101-7103.

Rodrigues, A.J., Leão, P., Carvalho, M., Almeida, O.F.X. \& Sousa, N. 2011. Potential programming of dopaminergic circuits by early life stress. Psychopharmacology 214, 107-120.

Rodrigues, A.J., Leão, P., Pêgom, J.M., Cardonam, D., Carvalho, M.M., Oliveira, M., Costa, B.M., Carvalho, A.F., Morgado, P., Araújo, D., Palha, J.A., Almeida, O.F.X. \& Sousa, N. 2012. Mechanisms of initiation and reversal of drug-seeking behavior induced by prenatal exposure to glucocorticoids. Mol Psychiatry 17, 1295-1305.

Rutter, M. 2012. Achievements and challenges in the biology of environmental effects. Proc Natl Acad Sci 109(Suppl 2), 17149-17153.

Rutter, M., O'Connor, T.G. \& English and Romanian Adoptees (ERA) Study Team. 2004. Are there biological programming effects for psychological development? Findings from a study of Romanian adoptees. Dev Psychol 40, 81-94.

Sameroff, A. 2010. A unified theory of development: a dialectic integration of nature and nurture. Child Dev 81, 6-22.

Sampey, B.P., Vanhoose, A.M., Winfield, H.M., Freemerman, A.J., Muehlbauer, M.J., Fueger, P.T., Newgard, C.B. \& Makowski, L. 2011. Cafeteria diet is a robust model of human metabolic syndrome with liver and adipose inflam- 
mation: comparison to high-fat diet. Obesity (Silver Spring) 19, 109-917.

Santos, N.C., Costa, P.S., Cunha, P., Cotter, J., Sampaio, A., Zihl, J., Almeida, O.F.X., Cerqueira, J.J., Palha, J.A. \& Sousa, N. 2012. Mood is a key determinant of cognitive performance in community-dwelling older adults: a crosssectional analysis. Age (Dordr) [Epub ahead of print].

Sapolsky, R.M. \& Meaney, M.J. 1986. Maturation of the adrenocortical stress response: neuroendocrine control mechanisms and the stress hyporesponsive period. Brain Res 396, 64-76.

Schatzberg, A.F. \& Lindley, S. 2008. Glucocorticoid antagonists in neuropsychiatric [corrected] disorders. Eur J Pharmacol 583, 358-364.

Scott, K.M., McGee, M.A., Wells, J.E. \& Oakley Browne, M.A. 2008. Obesity and mental disorders in the adult general population. J Psychosom Res 64, 97-105.

Selye, H. 1998. A syndrome produced by diverse nocuous agents. 1936. J Neuropsychiatry Clin Neurosci 10, 230-231.

Seok, J., Warren, H.S., Cuenca, A.G., Mindrinos, M.N., Baker, H.V., Xu, W., Richards, D.R., McDonald-Smith, G.P., Gao, H., Hennessy, L. et al. 2013. Genomic responses in mouse models poorly mimic human inflammatory diseases. Proc Natl Acad Sci 110, 3507-3512.

Sheridan, M.A., Fox, N.A., Zeanah, C.H., McLaughlin, K.A. \& Nelson, C.A. III 2012. Variation in neural development as a result of exposure to institutionalization early in childhood. Proc Natl Acad Sci 109, 12927-12932.

Sinha, R. \& Jastreboff, A.M. 2013. Stress as a common risk factor for obesity and addiction. Biol Psychiatry 73, 827-835.

Smyke, A.T., Zeanah, C.H., Fox, N.A., Nelson, C.A. \& Guthrie, D. 2010. Placement in foster care enhances quality of attachment among young institutionalized children. Child Dev 81, 212-223.

Sotiropoulos, I., Catania, C., Pinto, L.G., Silva, R., Pollerberg, G.E., Takashima, A., Sousa, N. \& Almeida, O.F.X. 2011. Stress acts cumulatively to precipitate Alzheimer's disease-like tau pathology and cognitive deficits. J Neurosci 31, 7840-7847.

Sousa, N. \& Almeida, O.F.X. 2012. Disconnection and reconnection: the morphological basis of (mal)adaptation to stress. Trends Neurosci 35, 742-751.

Sousa, N., Almeida, O.F.X. \& Wotjak, C.T. 2006. A hitchhiker's guide to behavioral analysis in laboratory rodents. Genes Brain Behav 5(Suppl 2), 5-24.
Strine, T.W., Mokdad, A.H., Dube, S.R., Balluz, L.S., Gonzalez, O., Berry, J.T., Manderscheid, R. \& Kroenke, K. 2008. The association of depression and anxiety with obesity and unhealthy behaviors among community-dwelling US adults. Gen Hosp Psychiatry 30, 127-137.

Sullivan, R.M. 2003. Developing a sense of safety: the neurobiology of neonatal attachment. Ann N Y Acad Sci 1008, 122-131.

Tilders, F.J., Berkenbosch, F., Vermes, I., Linton, E.A. \& Smelik, P.G. 1985. Role of epinephrine and vasopressin in the control of the pituitary-adrenal response to stress. Fed Proc 44, 155-160.

Toga, A.W., Thompson, P.M. \& Sowell, E.R. 2006. Mapping brain maturation. Trends Neurosci 29, 148-159.

Tsankova, N., Renthal, W., Kumar, A. \& Nestler, E.J. 2007. Epigenetic regulation in psychiatric disorders. Nat Rev Neurosci 8, 355-367.

Unternaehrer, E., Luersm, P., Millm, J., Dempsterm, E., Meyerm, A.H., Staehlim, S., Lieb, R., Hellhammer, D.H. \& Meinlschmidt, G. 2012. Dynamic changes in DNA methylation of stress-associated genes (OXTR, BDNF) after acute psychosocial stress. Transl Psychiatry 2, e150.

Vanderwert, R.E., Marshall, P.J., Nelson, C.A. III, Zeanah, C.H. \& Fox, N.A. 2010. Timing of intervention affects brain electrical activity in children exposed to severe psychosocial neglect. PLOS ONE 5, e11415.

Wells, J.C. 2007. Flaws in the theory of predictive adaptive responses. Trends Endocrinol Metab 18, 331-337.

Wouters, E.J., Larsen, J.K., Dubas, J.S. \& Geenen, R. 2011. Different mechanisms underlie post-menarchial increase in depression and weight. Int J Behav Med 18, 254-259.

Wyrwoll, C.S., Holmes, M.C. \& Seckl, J.R. 2011. $11 \beta$-hydroxysteroid dehydrogenases and the brain: from zero to hero, a decade of progress. Front Neuroendocrinol $32,265-286$.

Xu, W.L., Atti, A.R., Gatz, M., Pedersen, N.L., Johansson, B. \& Fratiglioni, L. 2011. Midlife overweight and obesity increase late-life dementia risk: a population-based twin study. Neurology 76, 1568-1574.

Zhang, T.Y., Labonté, B., Wen, X.L., Turecki, G. \& Meaney, M.J. 2013. Epigenetic mechanisms for the early environmental regulation of hippocampal glucocorticoid receptor gene expression in rodents and humans. Neuropsychopharmacology 38, 111-123. 